\title{
ANTARCTIC SEA-ICE FREEBOARD AND ESTIMATED THICKNESS FROM NASA'S ICESAT AND ICEBRIDGE OBSERVATIONS
}

\author{
Donghui $\mathrm{Yi}^{1}$, Nathan Kurtz ${ }^{2}$, Jeremy Harbeck ${ }^{3}$, Serdar Manizade ${ }^{4}$, Michelle Hofton ${ }^{5}$, \\ Helen G. Cornejo ${ }^{1}$, H. Jay Zwally ${ }^{2,6}$, and John Robbins ${ }^{7}$ \\ ${ }^{1}$ SGT Inc., Cryospheric Sciences Laboratory, Code 615, NASA/GSFC, Greenbelt, MD 20771, USA \\ (e-mail: donghui.yi@nasa.gov) \\ ${ }^{2}$ Cryospheric Sciences Laboratory, Code 615, NASA/GSFC, Greenbelt, MD 20771, USA \\ ${ }^{3}$ ADNET Systems Inc., Cryospheric Sciences Laboratory, Code 615, NASA/GSFC, Greenbelt, MD 20771, USA \\ ${ }^{4}$ URS Corporation, Cryospheric Sciences Laboratory, Code 615, NASA/WFF, Wallops Island, VA 23337, USA \\ ${ }^{5}$ Department of Geographical Sciences, University of Maryland, College Park, MD 20742, USA \\ ${ }^{6}$ ESSIC, University of Maryland, College Park, MD 20742, USA \\ ${ }^{7}$ Craig Technologies, Cryospheric Sciences Laboratory Code 615, NASA/GSFC, Greenbelt, MD 20771, USA
}

\section{INTRODUCTION}

ICESat completed 18 observational campaigns during its lifetime from 2003 to 2009. Data from all of the 18 campaign periods are used in this study. Most of the operational periods were between 34 and 38 days long. Because of laser failure and orbit transition from 8-day to 91-day orbit, there were four periods lasting 57, 16, 23, and 12 days [1]. IceBridge data from 2009, 2010, and 2011 are used in this study. Since 2009, there are 19 Airborne Topographic Mapper (ATM) campaigns [2], [3] and eight Land, Vegetation, and Ice Sensor (LVIS) campaigns [4] over the Antarctic sea ice. Freeboard heights are derived from ICESat, ATM and LVIS elevation and waveform data. With nominal densities of snow, water, and sea ice, combined with snow depth data from AMSR-E/AMSR2 passive microwave observation [5] over the southern ocean, sea-ice thickness is derived from the freeboard.

Combined with AMSR-E/AMSR2 ice

concentration, sea-ice area and volume are also calculated. During the 2003-2009 period, sea-ice freeboard and thickness distributions show clear seasonal variations that reflect the yearly cycle of the growth and decay of the Antarctic pack ice. We found no significant trend of thickness or area for the Antarctic sea ice during the ICESat period. IceBridge sea ice freeboard and thickness data from 2009 to 201 lover the Weddell Sea and Amundsen and Bellingshausen Seas are compared with the ICESat results.

\section{METHODS}

The details of the method used in this paper to derive sea-ice freeboard from ICESat and ATM elevation profiles are described in Zwally et al. [1], Yi et al. [6], and Yi et al. [7]. As a brief summary, the technique of deriving freeboards uses segments of open water and thin ice detected by the laser altimeter to determine the height of the along-track sea surface, which is then used as the reference sea level for the freeboard heights of the snow-covered sea ice. Surface elevation $H$ is the surface height $\left(h_{e}\right)$ with geoid $\left(h_{\text {geoid }}\right)$, tides $\left(h_{\text {tides }}\right)$, dynamic atmospheric correction $\left(h_{d a c}\right)$, and instrument related correction $\left(\mathrm{h}_{\mathrm{ic}}\right)$ that related to ICESat and ATM removed.

$$
H=h_{e}-h_{\text {tides }}-h_{\text {geoid }}-h_{\text {dac }}-h_{i c} \text {. }
$$

Freeboard height, $F$, at a given point is defined as,

$$
F=H-h_{s} \text {. }
$$

$h_{s}$ is the detected reference sea level. According to Archimedes buoyancy principle, sea ice thickness $T_{I}$ is, 


$$
T_{I}=\frac{\rho_{W}}{\rho_{W}-\rho_{I}} H-\frac{\rho_{W}-\rho_{S}}{\rho_{W}-\rho_{I}} T_{S}
$$

$\rho_{S}, \rho_{W}$, and $\rho_{I}$ are densities for snow, water, and sea ice. $T_{S}$ is the snow depth from AMSRE/AMSR2 data product. The sea level, $h_{s}$, is calculated based on the ICESat and ATM observed open water or thin ice.

For ICESat, we assume that it can detect open water or thin ice in at least $2 \%$ in a $50 \mathrm{~km}$ section of a profile. $h_{s}$ at any given point is determined by averaging the lowest $2 \%$ of the $H$ values within $\pm 25 \mathrm{~km}$ of that point. It provides enough points in calculating mean sea level to reduce measurement noise, and also minimizes the influence of thinner ice on the calculation.

For ATM, elevation and waveform related parameters are used to determine open water or thin ice to calculate reference sea level. The waveforms of ATM were fitted with a Gaussian curve, $\mathrm{g}(\mathrm{t})$, with four parameters: signal baseline $\left(\mathrm{e}_{\mathrm{g}}\right)$, pulse amplitude $\left(\mathrm{A}_{\mathrm{g}}\right)$, peak location $\left(\mathrm{t}_{\mathrm{g}}\right)$, and 1 -sigma pulse width $\left(\mathrm{PW}=\sigma_{\mathrm{g}}\right)$. The Gaussian function with four parameters is expressed as:

$$
\mathrm{g}(\mathrm{t})=\mathrm{e}_{\mathrm{g}}+\mathrm{A}_{\mathrm{g}} \exp \left[-0.5\left(\mathrm{t}-\mathrm{t}_{\mathrm{g}}\right)^{2} / \sigma_{\mathrm{g}}{ }^{2}\right]
$$

Skewness (SK), kurtosis (KU), pulse area, and centroid location for each waveform were also calculated. An empirical parameter-limit filter is used to identify leads. Distributions of elevation $(\mathrm{H})$, the apparent reflectivity $(\mathrm{R})$, received waveform pulse width $\left(\mathrm{PW}_{\mathrm{R}}\right)$, skewness $\left(\mathrm{SK}_{\mathrm{R}}\right)$, and kurtosis $\left(\mathrm{KU}_{\mathrm{R}}\right)$ are calculated for a filter window of $20 \mathrm{~km}$. This filter window is moving along track in $2 \mathrm{~km}$ steps. Surface points that satisfy the conditions of: $\mathrm{H} \leq \mathrm{H}_{\mathrm{M}}-2 \sigma_{\mathrm{H}}, \mathrm{R} \leq \mathrm{R}_{\mathrm{M}}$ $2 \sigma_{\mathrm{R}}, \mathrm{PW}_{\mathrm{R}} \leq \mathrm{PW} \mathrm{RM}_{\mathrm{RM}}-2 \sigma_{\mathrm{PWR}}, \mathrm{SK}_{\mathrm{R}} \geq \mathrm{SK}_{\mathrm{RM}}+2 \sigma_{\mathrm{SKR}}$, and $K U_{R} \geq K U_{R M}+2 \sigma_{K U R}$, in a filter window are identified as leads. The mean of a parameter $\mathrm{X}$ for a filter window is denoted as $\mathrm{X}_{\mathrm{M}} . \sigma_{\mathrm{X}}$ is the one standard deviation of $\mathrm{X}$ values in a filter window.

ICESat data product GLA05 and GLA06 (https://nsidc.org/data/gla05 and https://nsidc.org/data/gla06) and ATM elevation product (https://nsidc.org/data/ilatmlb) located at
NSIDC and ATM waveform data are used in this study. The AMSR-E sea ice concentration and snow depth data are also from NSIDC.

\section{RESULTS}

We calculated Antarctic sea-ice freeboard and thickness for ICESat and ATM campaigns. A Gridded ATM freeboard map of nine IceBridge campaigns in October 2009, 2010, and 2011 is shown in Figure 1.

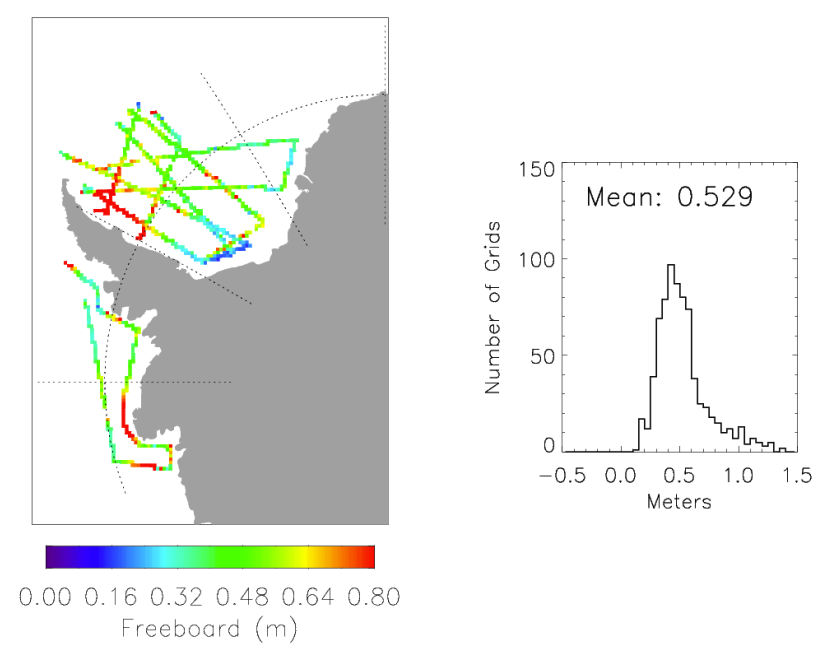

Figure 1. ATM shot to shot freeboards are gridded to a $25 \times 25 \mathrm{~km}$ grid. The histogram is the gridded freeboard distribution for all nine October campaigns from 2009, 2010, and 2011. The mean freeboard for the covered area in October is 0.529 meters.

ICESat sea-ice freeboards and thickness for data release 34 are shown in Figure 2. The seasonal sea-ice area variation is clearly presented for every year of the observations from 2003 to 2009. The area minimum is in the February-March (FM) periods. For the seven FM periods, the mean freeboards are $0.33-0.45 \mathrm{~m}$ and the mean thickness are 1.87-2.86 m. Large portions of thin ice formed in the May-June periods (MJ). For the three $\mathrm{MJ}$ periods, the mean freeboards vary from 0.27 to $0.30 \mathrm{~m}$ and the mean thickness vary from 1.68 to $1.99 \mathrm{~m}$. Maximum areas are in the October-November periods (ON). For the ON periods, the mean freeboards are $0.34-0.37 \mathrm{~m}$ and the mean thickness are $2.16-2.84 \mathrm{~m}$. 

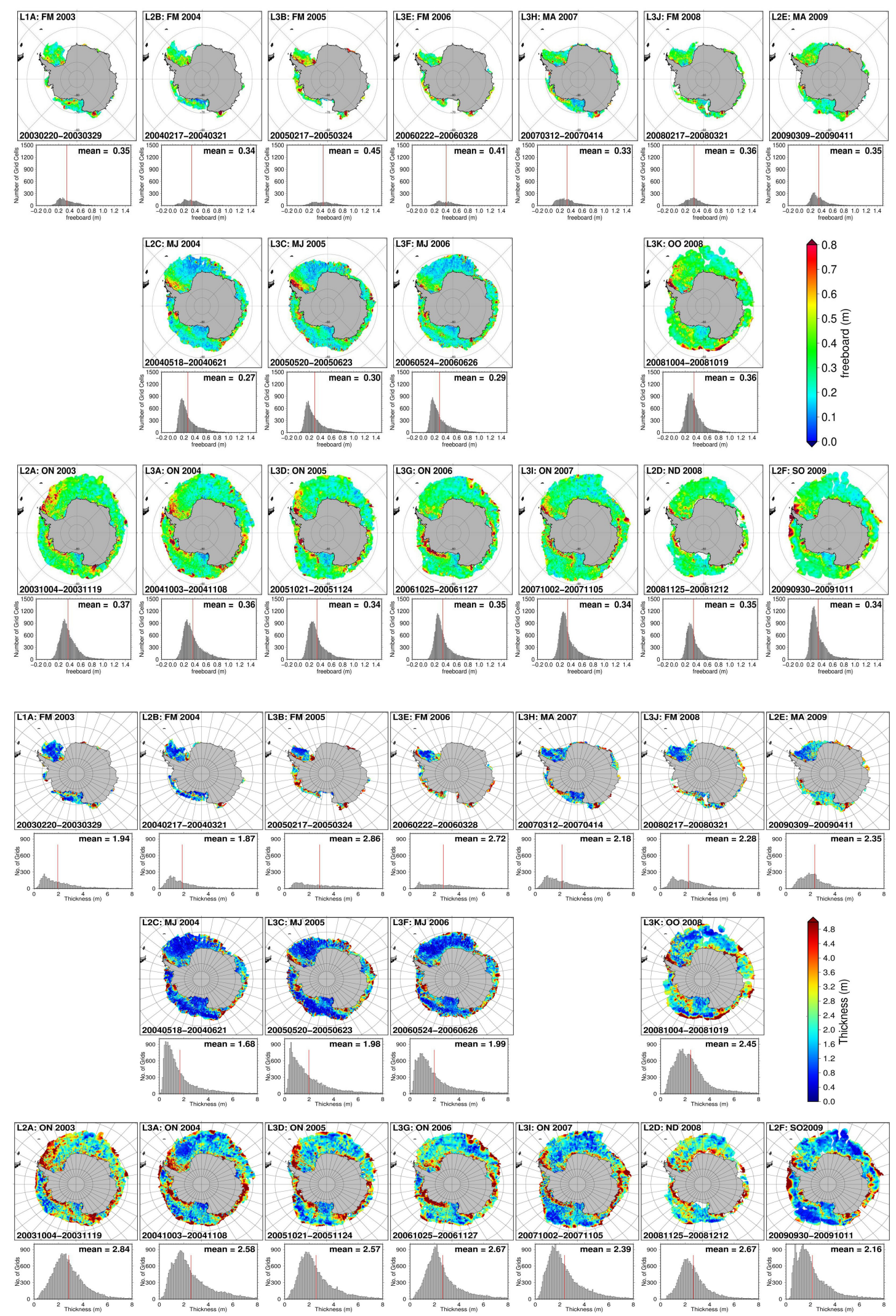

Figure 2. ICESat sea-ice freeboard and thickness maps and distributions from 2003 to 2009. 
Antarctic sea-ice extent AMSR-E and Volume from ICESat are shown in Figure 3. From 2003 to 2009 , the sea-ice extent has a small positive trend of $0.017 \pm 0.076\left(10^{6} \mathrm{~km}^{2}\right) / \mathrm{yr}$. The sea-ice volume has a small negative trend of $-0.016 \pm 0.353$ $\left(10^{3} \mathrm{~km}^{3}\right) / \mathrm{yr}$.
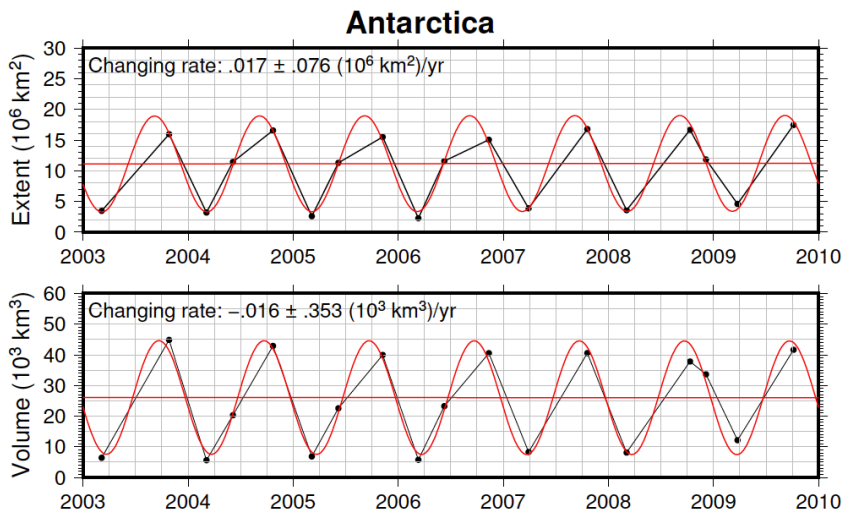

Figure 3. Antarctic sea-ice extent and volume from 2003 to 2009 . A sinusoidal curve with a 1-year period is fitted to the 18 points corresponding to the 18 ICESat campaigns for sea-ice extent or volume.

\section{REFERENCES}

[1] H. J. Zwally, D. Yi, R. Kwok, and Y. Zhao, "ICESat measurements of sea ice freeboard and estimates of sea ice thickness in the Weddell Sea," J. Geophys. Res., vol. 113, no. C2, pp. C02S15-1C02S15-17, Feb. 2008.

[2] W. B. Krabill, IceBridge ATM L1B Qfit Elevation and Return Strength. Boulder, CO, USA: NASA DAAC, National Snow and Ice Data Center, 2010. [Online]. Available: http://nsidc.org/data/ilatmlb.html.

[3] N. T. Kurtz, M.S. Studinger, J. Harbeck, V. Onana, and S. Farrell, Ice- Bridge Sea Ice Freeboard, Snow Depth, and Thickness. Boulder, CO, USA: NASA DAAC, National Snow and Ice Data Center, 2013.

[4] J. B. Blair and M. Hofton, IceBridge LVIS L2 Geolocated Surface Elevation Product. Boulder, CO, USA: National Snow and Ice Data Center, NASA DAAC, 2010. [Online]. Available: http://nsidc.org/data/ilvis2.html and http://nsidc.org/data/ilvis1b.html

[5] T. Markus and D. J. Cavalieri (1998), Snow depth distribution over sea ice in the southern ocean from satellite passive microwave data, In Jeffries, M. O. ed. Antarctic sea ice: physical process, interactions and variability, Washington, DC, American Geophysical Union, 19-39. (Antarctic Research Series 74.)

[6] D. Yi, H. J. Zwally, and J. W. Robbins, "ICESat observations of seasonal and interannual variations of sea-ice freeboard and estimated thickness in the Weddell Sea (2003-2009)," Ann. Glaciol., vol. 52, no. 57, pp. 43-51, May 2011.

[7] D. Yi, Jeremy P. Harbeck, Serdar S. Manizade, Nathan T. Kurtz, Michael Studinger, and Michelle Hofton. Arctic sea ice freeboard retrieval with waveform characteristics for NASA's Airborne Topographic Mapper (ATM) and Land, Vegetation, and Ice Sensor (LVIS). IEEE Transactions on Geoscience and Remote Sensing. VOL. 53, NO. 3, MARCH 2015, 10.1109/TGRS.2014.2339737. 